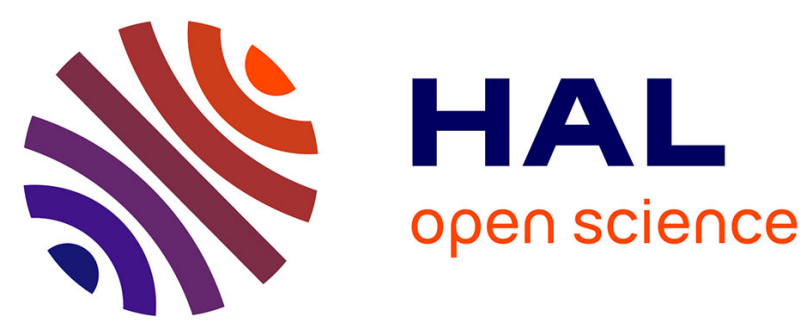

\title{
A dynamic lot-sizing-based profit maximization discounted cash flow model considering working capital requirement financing cost with infinite production capacity
}

Yuan Bian, David Lemoine, Thomas G. Yeung, Nathalie Bostel, Vincent Hovelaque, Jean-Laurent Viviani, Fabrice Gayraud

\section{To cite this version:}

Yuan Bian, David Lemoine, Thomas G. Yeung, Nathalie Bostel, Vincent Hovelaque, et al.. A dynamic lot-sizing-based profit maximization discounted cash flow model considering working capital requirement financing cost with infinite production capacity. International Journal of Production Economics, 2018, 196, pp.319-332. 10.1016/j.ijpe.2017.12.002 . halshs-01683781

\section{HAL Id: halshs-01683781 \\ https://shs.hal.science/halshs-01683781}

Submitted on 14 Jan 2018

HAL is a multi-disciplinary open access archive for the deposit and dissemination of scientific research documents, whether they are published or not. The documents may come from teaching and research institutions in France or abroad, or from public or private research centers.
L'archive ouverte pluridisciplinaire HAL, est destinée au dépôt et à la diffusion de documents scientifiques de niveau recherche, publiés ou non, émanant des établissements d'enseignement et de recherche français ou étrangers, des laboratoires publics ou privés. 
International Journal of Production Economics

Yuan BIAN

LS2N, UMR CNRS 6004,

IMT Altantique,

4, Rue Alfred Kastler, B.P. 20722, 44307 Nantes Cedex 3, France,

Phone : (0033)251858335

E-mail : yuan.bian@imt-atlantique.fr

Title: A dynamic lot-sizing-based profit maximization discounted cash flow model considering working capital requirement financing cost with infinite production capacity

Authors: Yuan BIAN ${ }^{\mathrm{a} *}$, David LEMOINE ${ }^{\mathrm{a}}$, Thomas G. YEUNG ${ }^{\mathrm{a}}$, Nathalie BOSTEL ${ }^{\mathrm{b}}$, Vincent HOVELAQUE ${ }^{c}$, Jean-laurent VIVIANI ${ }^{c}$, Fabrice GAYRAUD ${ }^{a}$

Affiliations:

a : LS2N, UMR CNRS 6004, IMT Altantique, 4, Rue Alfred Kastler, B.P. 20722, 44307 Nantes, France

b : LS2N, UMR CNRS 6004, University of Nantes, 58 rue Michel Ange, B.P. 420, 44606 SaintNazaire, France

c : CREM, UMR CNRS 6211, IGR-IAE of Rennes, University of Rennes 1, 11 rue Jean Macé, 35708 Rennes, France

* : Corresponding author 


\title{
A dynamic lot-sizing-based profit maximization discounted cash flow model considering working capital requirement financing cost with infinite production capacity
}

\begin{abstract}
In times of crisis, companies need free cash flow to efficiently react against all uncertainty to ensure solvency. However, classical dynamic lot-sizing models only consider the physical flow of goods. In this paper, we introduce a first link between dynamic lot-sizing and the financial aspects of working capital requirements (WCR). We propose a new generic WCR model which allows us to evaluate the company's financial situation throughout the planning horizon. Moreover, a dynamic lot-sizing-based, discounted cash flow model is established for single-site, single-level, single-product and infinite capacity cases. It is shown that the zero-inventory ordering property holds for this case and thus a polynomial-time algorithm may be utilized. Numerical tests are presented in order to show the relevance of our approach compared with the traditional dynamic lot-sizing model.

Keywords: profit maximization; dynamic lot-sizing; working capital requirement; discounted cash flow; delays in payment.
\end{abstract}

\section{Introduction}

According to the Ernst \& Young annual Working Capital Management (WCM) report of 2012 devoted to the leading 1000 US companies in year 2011, on average, $\$ 330$ billion dollars of Net Working Capital (NWC) is unnecessarily immobilized (see in Ernst (2012)). This range of cash opportunity corresponds to, respectively, between $3 \%$ and $6 \%$ of their aggregate sales. Buchmann et al. (2008) also stress that savings on Working capital Requirement (WCR) as a potential source of cash to fund growth is often neglected by companies. Suboptimal WCM not only reduces potential gains, it also raises companies' risk. A company needs to carefully Preprint submitted to International Journal of Production Economics 
manage its WCR in order to ensure financial liquidity or reduce insolvency risk. Additionally, optimal WCM can unlock internal capital and provide financial resources to financially constrained firms. Especially during the last financial crisis, bank loans were extremely difficult to obtain by companies, especially those in the development phase (see in Wu et al. (2016)). Many companies suffer from lack of credit and insufficient working capital. Small suppliers are forced to accept unfavorable payment terms from their customers, exacerbating their financial situation. Moreover, tight or unavailable bank credit reduces the working capital level of these companies. As a result, some companies must suspend their operations which can disrupt the whole supply chain as reported in Benito et al. (2010) and Ernst (2010).

In spite of its importance for firm (and more generally the supply chain) performance and survival, WCM has been neglected by the literature on production planning. More generally, as stated by Birge (2014), "Operations management models typically only consider the level and organization of a firms transformation activities without considering the financial implications of those activities". The separation of the operational decision (minimizing operational costs or maximizing operational profits) and financial decision (minimizing financial costs or maximizing financial profit) was theoretically grounded on the famous Modigliani and Miller (1958) theorem and practically by the functional organization of companies. However, in recent years, the literature on operations and supply chain management, following the original work of Babich and Sobel (2004), became aware of the fact that financing and operational problems are imbricated and that optimizing the two dimensions jointly could improve the global performance of the company as shown in Chen et al. (2014). A recent review of this literature based on a risk management framework has been proposed by Zhao and Huchzermeier (2015). Nevertheless, in the production planning field, the majority of models typically ignore the financial consequences of production planning decisions. In an attempt to fill this gap, the aim of the paper is to explicitly introduce the financial dimension in a tactical production planning model.

Traditionally, tactical production planning aims at determining the production quantity for each period of the planning horizon. It is often known for its strong influence in terms of customer service quality and production related operation costs. Two main classes of models distin- 
guish the problem based on continuous/discrete time considerations: for example, with infinite capacity, the Economic Order Quantity (EOQ) model of Harris (1913) for constant demand over continuous time and the Uncapacitated Lot-Sizing model (ULS) of Wagner and Whitin (1958) for time-varying demand over discrete time. Readers can refer to the literature review of Brahimi et al. (2017) for single item cases and of Comelli et al. (2006) for model classification. However, production planning is determined following the well-known Manufacturing Resource Planning (MRP II) logic for a medium-term objective. As indicated by Helber (1998), this decision does not reflect difference in Net Present Value (NPV) of cash flow due to planned operations in real world market system. Moreover, financial aspects are rarely considered in dynamic lot-sizing literature.

In order to better take into account the financial dimension in a production planning context, we first replace the total operational cost minimization objective by the overall financial objective of the firm, which is the wealth maximization objective. The total wealth represents the sum of the net present values of all future cash flows. This remains the main stream objective in corporate finance as stated in Jensen (2001). The importance of this objective has also been recognized in the production planning literature (see Serrano et al. (2017)).

Second, we introduce a joint management of both physical and financial flows within a discounted cash flow-based dynamic LSP model. We consider both classical operational costs (e.g., purchasing, setup, production) and financial costs. More specifically, financial costs are generated by the need to finance the Working Capital Requirement(WCR) induced by operational decisions. In practice, the WCR is known as a key indicator to monitor and control a company's financial situation. The WCR is mainly caused by the timing mismatch between the cash inflows and the cash outflows associated with the total production and commercial cycle as presented in Theodore Farris and Hutchison (2002). According to the cash conversion cycle methodology proposed by these authors, the free cash flow level can be approximately measured as the difference between the working capital and WCR. As a consequence, a lower operating WCR gives the company better liquidity and helps to ensure solvency. By this direct link with cash flow, the WCR increasingly draws the attention of finance departments in a financial crisis context. 
By introducing the financing cost of the WCR, the traditional trade-off between set-up costs and inventory costs is therefore modified. If the company orders lots of bigger size, it will not only increase inventory costs, but also the WCR, leading to higher financial costs.

The main contributions of this paper are the following:

- First, we propose a WCR model adapted to the production planning context. This allows us to precisely measure the WCR during the planning horizon;

- Second, we demonstrate that the Zero-Inventory-Ordering property remains valid in this problem. This ensures a strong structural property of the optimal solution and its exact resolution in polynomial time. Moreover, it shows no additional computational complexity by introducing the financial cost into the optimization objective;

- Finally, we show significant differences between optimal production planning obtained by the classic dynamic lot-sizing model and our proposed model.

This remainder of this paper is organized as follows: In Section 2, related works that consider a financial aspect in tactical production planning and profit maximization models are reviewed. In Section 3, we propose a generic model of operating WCR in a tactical production planning context. We then develop a profit maximization model based on a classic dynamic LSP model by using the OWCR model for the single-product with infinite capacity case. In Section 4, the ZeroInventory-Ordering property is proven and a dynamic programming algorithm is consequently established. In Section 5, we analyze the differences of both the optimal production planning of the proposed model and the classical dynamic lot-sizing model in terms of production planning. We end with a short conclusion and show insights for further research.

\section{Literature Review}

The management of financial flow is an important part of supply chain management (SCM) as shown in Cooper et al. (1997) and Vidal and Goetschalckx (2001). However, formal analytical models have only recently become available in Raghavan and Mishra (2011) and Liu and Cruz (2012). They aim to understand how the planning, management and control of financial flows in 
supply chains affect the chain profitability. In addition, inventory management models have been reformulated to take into account financial considerations such as trade credit, delay in payment or financial risks, as in Aggarwal and Jaggi (1995), Berling and Rosling (2005) and Gupta and Wang (2009). Moreover, Protopappa-Sieke and Seifert (2010) elaborate on the interest of considering decision making in both operational and financial levels for the physical and financial supply chain by determining the optimal purchase order quantity. In addition, Zeballos et al. (2013) explain the evolution of the Modigliani and Miller theorem in the field of inventory management and propose a single-product, finite horizon model that considers the financial aspects of working capital constraints, payment delays and short-term debts. These studies highlight the fact that in supply chain management, physical flow and financial information must be managed jointly.

We consider WCR in tactical production planning because working capital management (WCM) has been identified as an important indicator for measuring supply chain performance by Timme and Williams-Timme (2000). The influence of WCM on a company's performance and profitability have been confirmed by several national studies by Ding et al. (2013), Enqvist et al. (2014), Vahid et al. (2012) and Bei and Wijewardana (2012) and in different industrial sectors, e.g., the restaurant and automotive industry in Lind et al. (2012) and Mun and Jang (2015), respectively. In addition, Kieschnick et al. (2013) report that for the average firm the incremental dollar invested in net working capital is worth less than the incremental dollar held in cash. Since free cash flow level is the difference between working capital level and the WCR level, if the working capital remains constant, the minimum level of WCR represents the maximum level of free cash flow. According to the accounting formula of WCR in finance, delays in payment both from the customer and to the supplier significantly influence the level of WCR. In practice, such a delay is often accepted by the supplier to the customer in the form of trade credit.

Furthermore, as a financial consideration, the time value of money has drawn significant attention for building cash flow analysis models, namely the Discounted Cash Flow (DCF) model. The Net Present Value (NPV) metric is adopted to measure the present value of future cash flow in order to calculate the profitability of a projected investment or project. Since the work of Trippi 
and Lewin (1974), the time value of money aspect has been largely addressed based on the classic EOQ model. More related works are discussed in reviews of Taleizadeh and Nematollahi (2014) and Martínez-Costa et al. (2014). In the single-site dynamic lot-sizing literature, the DCF models can also be found since the work of Helber (1998) in various industry contexts. The author develops a cash-flow oriented multi-level lot-sizing model in MRP II (Manufacturing Resource Planning) system. Recently, Lim et al. (2013) establish a mathematical model in order to obtain the optimal product portfolio and the processing route of an integrated, resource-efficient rice mill complex with a profit maximization objective. Mitra et al. (2014) propose a Mixed Integer Linear Programming (MILP) formulation that combines the operational and strategic decisions for continuous power-intensive processes under time-sensitive electricity prices.

In addition, the aspect of working capital has often been considered in term of capital or budget constraints in inventory management literature. Recently, Wang et al. (2007a) address the acquisition and allocation of LCD (Liquid-Crystal Display) manufacturing industries which requires a high amount of capital investments. In this problem, the authors included not only constraints of operational aspect, e.g., resource capacity constraints and backorder, but also financial aspects of finite budget and the time value of capital and asset. Wang et al. (2007b) propose a mathematical programming model for a generalized resource portfolio problem in a context of the semiconductor testing industry considering the financial resource constraints and the time value of capital. Chao et al. (2008) study the influence of loan limits on the operation decision in the EOQ context. Thomas and Bollapragada (2010) develop an analytical decision tool based on a capacity planning model to estimate product costs and demands in order to maximize the NPV of profit for General Electric. Lusa et al. (2012) develop a MILP formulation of an integral planning model with a maximum level of working capital constraints.

In this paper, therefore, we are interested in proposing a new generic operating WCR (OWCR) model in a tactical planning framework for a dynamic LSP model. For this reason, we propose a DCF-based profit maximization model considering the upstream and downstream payment delays and the financing cost of OWCR. A comparison between the aforementioned single-site dynamic lot-sizing-based models and our research is presented in Table 1. MinC stands for cost 
minimization objective and MaxP stands for profit maximization objective.

\begin{tabular}{|c|c|c|c|c|c|}
\hline Authors & $\begin{array}{l}\text { Finite } \\
\text { budget }\end{array}$ & $\begin{array}{c}\text { Time value } \\
\text { of money }\end{array}$ & $\begin{array}{l}\text { Delay of } \\
\text { payment }\end{array}$ & WCR & Objective \\
\hline Helber (1998) & & $\sqrt{ }$ & & & MinC \\
\hline Wang et al. (2007a) & $\sqrt{ }$ & $\sqrt{ }$ & & & MaxP \\
\hline Wang et al. (2007b) & $\sqrt{ }$ & $\sqrt{ }$ & & & MaxP \\
\hline Thomas and Bollapragada (2010) & $\sqrt{ }$ & $\sqrt{ }$ & & & MaxP \\
\hline Lusa et al. (2012) & $\sqrt{ }$ & $\sqrt{ }$ & & & MaxP \\
\hline Lim et al. (2013) & & $\sqrt{ }$ & & & MaxP \\
\hline Mitra et al. (2014) & & $\sqrt{ }$ & & & MinC \\
\hline This work & & $\sqrt{ }$ & $\sqrt{ }$ & $\sqrt{ }$ & MaxP \\
\hline
\end{tabular}

Table 1: Comparison with single-site models in the dynamic lot-sizing literature

\section{Discounted cash flow based profit maximization model}

\subsection{OWCR modeling}

The discounted cash flows method explicitly takes into account the time difference between the cash flows but it does not take into account the financial borrowing costs because these costs, in traditional models, are often supposed not to affect the optimal operational decision. As we challenge this assumption, we want to integrate only the financial costs linked to operational decisions in the cash flows (i.e., financing cost of OWCR). To do so, we propose a generic OWCR formulation in a tactical planning context. In this formulation, both the delay in payment to supplier and from client are taken into account and the time value of money is considered in order to calculate present values of incoming and outgoing cash flows. Furthermore, it should be possible to measure the level of inventory precisely over the planning horizon with this OWCR formulation as inventory holding costs make up a substantial portion of the OWCR.

We therefore adopt the cash to cash cycle methodology presented in Theodore Farris and Hutchison (2002) and Hofmann and Kotzab (2010) where the OWCR for producing a unit of product depends on the amount invested in the related operations (e.g., purchasing, setup, production and inventory holding) and the number of periods to finance these investments before recovering from corresponding sales. However, we first consider that the profit portion of the sales revenue is not available to cover the OWCR. This is because the company's profit margin does 
not correspond to the definition of working capital requirement since it has never been required. Furthermore, this assumption supposes that the company does not prioritize its profit allocation to WCR financing. Profit can be allocated to any of a number of objectives for the firm including debt reduction, internal or external investment, or dividend payments. Our model is a partial model of the company and we do not assume that allocation of profit to WCR financing rather than to other objectives (e.g., new investments) is optimal. Moreover, following the Modigliani Miller Theorem, a company should not allocate a specific financial resource (in this case, profit) to a specific object (in this case, WCR financing). In consequence, we adopt the scheme that the WCR generated by producing a product is only effectively recovered when that product is sold.

This assumption complicates the calculation of the financing duration of setup costs because it is paid in its entirety at a single point in time for the entire production lot. Thus, we must progressively and uniformly recover the setup cost from the sales revenue of all products in the same production lot. These products therefore share the fixed setup cost equally as the amount invested and the number of periods to finance is the time difference between the period when the setup occurs and the period of sale of each product.

\subsection{Assumptions}

Since this model is built in the context of the ULS (Uncapacitated Lot-Sizing) problem, the OWCR formulation and the corresponding profit maximization model proposed in this paper are based on the following assumptions:

- Production:

- No replenishment and production delays as they are negligible compared with period duration;

- Demand should be met on time (no backlogging);

- Only inventory of final product is considered;

- Initial and final stock are defined as zero;

- One unit of finished product is manufactured using one unit of raw material. 
- Financial:

- All logistic and financial costs are paid at the beginning of periods;

- The profit from selling products is not be used for financing the OWCR;

- The fixed setup cost of a given lot is progressively and uniformly recovered over the different periods during which the products of the corresponding lot are sold;

- All holding costs paid for a product for all periods it remains in inventory are not recovered until it's sale.

\subsection{Physical and financial flow illustration}

With the aforementioned assumptions, we express in detail in Figure 1, the physical and financial flows generated by a production in period 1 for the demand of period 3 . In this case, we assume the delays in payment from client and to supplier are both one period.

- Physical flows are presented in the top block. They are generated by decisions made in the operating cycle, such as purchase, production, inventory holding and delivery. Therefore, the physical flows link all decisions in the graphic with the single line arrow.

- The financial flows are displayed in the bottom block. First, the logistic costs are immediately generated by the physical activities presented by small squares in the financial block. Meanwhile, the WCR financing costs are also to be paid from the same period of corresponding logistic costs until the reception of revenue. These financial costs are presented with the double line arrow.

\subsection{Parameters and decision variables}

In this model, parameters and decision variables are adopted for the single-site, single-level, single-product with infinite capacity case. Their notations are given in Tables 2 and 3 respectively. We assume that these parameters are all nonnegative. We choose the decision variables of the FAL (FAcility Location) formulation of the ULS. These disaggregated variables allow us to measure the exact amount of incoming and outgoing payments for all production related operations considered for calculating the OWCR. 


\begin{tabular}{ll}
\hline Parameter & Definition \\
\hline$T$ & Horizon length \\
$d_{t}$ & Demand in period $t$ \\
$v$ & Unit product price \\
$h$ & Unit inventory cost per period \\
$p$ & Unit production cost \\
$s$ & Fixed setup cost \\
$a$ & Unit raw material cost \\
$r_{c}$ & Delay in payment from client \\
$r_{f}$ & Delay in payment to supplier \\
$\alpha$ & Discount rate per period \\
$\beta$ & Interest rate for financing \\
& OWCR per period \\
\hline
\end{tabular}

Table 2: Parameters for OWCR modeling

\begin{tabular}{ll}
\hline Variable & Definition \\
\hline$Q_{t}$ & $\begin{array}{l}\text { Total production quantity } \\
\text { in period } t\end{array}$ \\
$X_{t k}$ & $\begin{array}{l}\text { Production quantity in pe- } \\
\text { riod } t \text { for satisfying (a part } \\
\text { of) demand in period } k\end{array}$ \\
& $\begin{array}{l}\text { Product quantity held in } \\
\text { inventory in period } t\end{array}$ \\
$I_{t}$ & $\begin{array}{l}\text { Binary variable which in- } \\
\text { dicates whether a setup } \\
\text { occurs in period } t \text { or not }\end{array}$ \\
$Y_{t}$ & Table 3: Decision variables for OWCR modeling
\end{tabular}

\subsection{Mathematical formulation}

In our problem, OWCR includes all financial needs for the operations of purchasing, setup, production and inventory holding for satisfying a known, but variable demand in an operation cycle. The financial need of each $X_{t k}$ is modeled as the product of the corresponding operation cost and the number of periods to finance.

- The operation cost is a function of the operation unit cost and the value of $X_{t k}$. All unit costs of purchasing raw material, production and inventory holding are given as parameters. However, all products in an $X_{t k}$ share the setup cost. The setup unit cost per product is thus $\frac{s}{Q_{t}}$. However, when $Q_{t}=0$, there is a problem of singularity. For this reason, it must be further reformulated as $\frac{s Y_{t}}{Q_{t}+\left(1-Y_{t}\right)}$ to prevent this issue. Consequently, if $Q_{t}=0, Y_{t}$ will then be zero. The denominator will be one. If $Q_{t}>0$, then $Y_{t}=1$ which leads to $\frac{s Y_{t}}{Q_{t}+\left(1-Y_{t}\right)}=\frac{s}{Q_{t}}$. Nevertheless, due to this non-linear formulation, we should check that the Zero-Inventory-Ordering (ZIO) property of this model still holds in order to establish an efficient solution algorithm.

- The number of periods to finance depends firstly on the difference between $k$ and $t$. Furthermore, the mismatch between payment to the supplier and payment from the client may extend the number of periods of the horizon beyond the last demand for financing the production related costs. The payment delays (i.e., $r_{c}$ and $r_{f}$ ) are introduced as parameters 
in order to quantify this mismatch. Using these parameters, we define the start period to finance the corresponding production related costs as well as the end period, as presented in Table 4.

\begin{tabular}{c|ccc|cccc}
\multirow{2}{*}{ Operations } & \multicolumn{3}{|c|}{ Operation cost } & \multicolumn{4}{c}{ Periods to finance } \\
\cline { 2 - 7 } & Unit cost & $\times$ & Quantity & from & $\left.\begin{array}{c}\text { the period of } \\
\text { outgoing payment }\end{array}\right)$ & until & $\begin{array}{c}\text { the period of } \\
\text { incoming payment }\end{array}$ \\
\hline Purchasing & $\mathrm{a}$ & $\times$ & $X_{t k}$ & from & $\left(t+r_{f}\right)$ & until & $\left(k+r_{c}-1\right)$ \\
\hline Setup & $\frac{s Y_{t}}{Q_{t}+\left(1-Y_{t}\right)}$ & $\times$ & $X_{t k}$ & from & $t$ & until & $\left(k+r_{c}-1\right)$ \\
\hline Production & $\mathrm{p}$ & $\times$ & $X_{t k}$ & from & $t$ & until & $\left(k+r_{c}-1\right)$ \\
\hline Inventory holding & $\mathrm{h}$ & $\times$ & $X_{t k}$ & \multicolumn{3}{c}{ Financing periods (FP) } \\
\end{tabular}

Although the costs of purchasing, set-up and production are all one-time payments for each production lot, the inventory holding cost is paid regularly in all periods where the stock is held in inventory. For this reason, there is a cumulative effect of financing the inventory holding costs. Assuming that a production lot covers all demands from period $t$ to period $k$ means that the production occurs in period $t$ at the latest. A unit of product of the demand in period $k$ will be sold in period $k$ and the client's payment will arrive in period $k+r_{c}$. The inventory holding cost for this item should be paid consequently from period $t$ until period $k-1$ (noted as "OWCR $R_{i n v}$ series"). The first of these payments occurs in period $t$ and must be financed until period $k+r_{c}-1$ (before the arrival of the client's payment, so a total of $k+r_{c}-t$ periods must financed). The second is paid in period $t+1$ until the same period of $k+r_{c}-1$ (in total, $k+r_{c}-(t+1)$ periods to finance.), etc. Consequently, for each $X_{t k}$, the financing period is $\frac{1+(k-t)}{2}(k-t)+r_{c}(k-t)$ periods including all periods to finance before and after the demand delivery.

Following this formulation of OWCR, the OWCR at period $t$, written as $O_{t}$, can be expressed in the following:

$$
\begin{aligned}
O_{t}= & a \sum_{j=1}^{t-r_{f}} \sum_{l=t-r_{c}+1}^{T} X_{j, l}+p \sum_{j=1}^{t} \sum_{l=t-r_{c}+1}^{T} X_{j, l}+s \sum_{j=1}^{t} \sum_{l=t-r_{c}+1}^{T} \frac{Y_{j}}{Q_{j}+\left(1-Y_{j}\right)} X_{j, l} \\
& +h \sum_{j=1}^{t} \sum_{l=t-r_{c}+1}^{T} X_{j, l} \cdot(\min \{l, t+1\}-j)
\end{aligned}
$$


The formulation $\sum_{j=1}^{t-r_{f}} \sum_{l=t-r_{c}-1}^{T} X_{j, l}$ represents all products whose production related operations still have to be financed at period $t$ considering the payment delays. Especially for measuring the total amount of inventory holding cost to finance at period $t$, we need to count the number of completed payments in the $O W C R_{i n v}$ series until period $t$ for each $X_{j, l}$. However, we must consider whether or not we have sold the products of $X_{j, l}$ before reception of the client's payment (in other words, whether or not $X_{t k}$ is still in inventory). $\min \{l, t+1\}-j$ precisely represents the total number of all payments for these two possible cases. The difference between these two cases as presented in formulation (1) is:

- If we have sold $X_{t k}$ at period $t$ (i.e. $l \leq t<l+r_{c}$ ), then the total amount to finance for inventory holding will not change during the periods before arrival of the client's payment. This is because we no longer need to pay the inventory holding cost for $X_{t k}$ in these periods. Thus, no additional inventory hold cost must be financed which means the total amount is a function of $l-j$.

- On the contrary, if the $X_{t k}$ is still in inventory (i.e. $j \leq t<l$ ), then the total amount of inventory holding costs to finance depends on $t+1-j$.

This formulation of OWCR allows us to follow the variation of OWCR over time in the planning horizon. It will be used in the following section for calculating the financing cost of OWCR.

\subsection{Objective function}

The objective of this problem is to maximize the NPV of the profit (denoted by Profit) by satisfying variable demand. To simplify the problem, the NPV of profit is defined as the difference between the NPV of revenue and the NPV of expenses. In our model, the revenue per period is a function of constant unit sales prices and demand quantity. The expenses include the production costs and the OWCR financing costs. The production cost is the sum of the costs for raw material purchasing, machine setup, production and inventory holding. The OWCR financing cost depends on the interest rate and the OWCR for satisfying all the demand on-time. Considering the payment delays, the planning horizon must be extended to the period when 
the last incoming or outgoing cash flow occurred. Mathematically, this accounting horizon is presented as $T+\max \left\{r_{f}, r_{c}\right\}$. For simplification purposes, $T$ denotes the accounting horizon in this paper. Since the time value of money is considered in this model, both cash inflow (i.e., revenues) and outflow (i.e., expenses) are presented in NPV as follows:

- NPV of revenue in period $t, R_{t}$ : due to the delay of the client's payment, we only receive the client's payment for the demand of period $t-r_{c}$ in period $t$. Thus, $R_{t}=\frac{1}{(1+\alpha)^{\prime}} v D_{t-r_{c}}$.

- NPV of production cost in period $t, L C_{t}$ : all expenses of production related operations must be paid immediately when they occur except for the purchasing cost which can be delayed $r_{f}$ periods according to the supplier agreement. Therefore, $L C_{t}=\frac{1}{(1+\alpha)^{t}}\left(a Q_{t-r_{f}}+\right.$ $\left.p Q_{t}+s Y_{t}+h I_{t}\right)$ with $Q_{t}=\sum_{k=t}^{T} X_{t k}$ and $I_{t}=\sum_{l=1}^{t} \sum_{k=t+1}^{T} X_{l k}$.

- NPV of OWCR financing cost in period $t, F C_{t}$ : The OWCR financing cost depends only on the interest rate per period and the amount of financial need (i.e., $O_{t}$ ) to cover in period t. $F C_{t}=\frac{1}{(1+\alpha)^{\prime}} \beta O_{t}$.

By summing over all periods of the accounting horizon, the objective function is formulated as follows:

$$
\text { Profit }=\sum_{t=1}^{T}\left(R_{t}-L C_{t}-F C_{t}\right)
$$

\section{7. $U L S_{P(W C R)}$ model}

A mixed-integer model of the profit maximization problem, $U L S_{P(W C R)}$, is formulated as follows:

$$
\begin{array}{lll}
\text { Max } & \text { Profit } \\
\text { s.t. } & Q_{t}=\sum_{k=t}^{T} X_{t k} & \forall t \\
& d_{k} Y_{t}-X_{t k} \geq 0 & \forall t, k \\
& Y_{t}-Q_{t} \leq 0 & \forall t \\
& \sum_{t=1}^{k} X_{t k}=d_{k} & \forall k \\
& X_{t k} \geq 0, Y_{t} \in\{0,1\} & \forall t, k
\end{array}
$$


The objective function is to maximize the NPV of total profit. The constraints are similar to those of the FAL formulation of the ULS. Constraints (1.2) indicate that $Q_{t}$ is the total quantity of production that occurs in period $t$. Constraints (1.3) ensure that a setup is executed before production. Constraints (1.4) prevent a setup from occurring in a period with no production. Finally, constraints (1.5) ensure that all demands are satisfied.

\section{Solution method}

In order to solve the $U L S_{P(W C R)}$ problem efficiently, we propose an algorithm which avoids the difficulty of the non-linear formulation of the setup cost in the OWCR calculation. This algorithm is similar to the algorithm which is based on the Zero-Inventory-Ordering (ZIO) property established for the ULS problem with infinite capacity by Wagner and Whitin (1958).

\subsection{Zero-Inventory-Ordering property}

In a ZIO-type planning, production is only planned when no products remain in the inventory. We demonstrate that an optimal solution can always be found within all possible plans that respect the ZIO property. Moreover, since only ZIO type plans need to be investigated to find the optimal solution, the number of feasible solutions to investigate is significantly reduced. The ZIO property can be expressed as follows:

Theorem: There exists an optimal production plan in which $I_{t-1} \times Q_{t}=0$ for all $t$ (where $I_{t}$ is the inventory at the end of the period $t)$ in $U L S_{P(B F R)}$ problem.

The proof is presented in Appendix A. The main idea is to demonstrate that we can always improve the objective value by eliminating violation(s) of the property by transforming a production plan which does not comply with the ZIO property to a ZIO-type plan. Eventually, we can prove the ZIO-type production program provides the optimal objective value.

\subsection{Algorithm description}

Since the demand, the delay in payment from the customers, and the discounted rate are all given, the NPV of revenue is fixed for each instance. Thus, we only need to minimize the NPV of all costs. Then, like the classical shortest path problem, the $U L S_{P(B F R)}$ problem is 
formulated with an acyclic oriented graph $G=\{V, E\}$ (see Figure 2). The nodes $V_{t}$ represent the $T$ periods in the planning horizon including a dummy node at the end (node 6 in Figure 2). Moreover, determining the production quantity benefits from the ZIO property which means that the production quantity can only be the sum of demands in the following periods. We thus avoid the difficulty caused by the nonlinear formulation of setup cost to finance. Consequently, an $\operatorname{arc} E_{t k}$ denotes a production planned in period $t$ for all demands between periods $t$ and $k-$ 1. With this concept and the ZIO property, we determine the precise quantity and period of a production as well as the delivery periods. We are thus able to deduce the period of client's payment for financial cost calculation. Finding a shortest path therefore allows us to obtain the optimal production program with the minimum total NPV of all costs generated. Furthermore, with the dummy node, we are able to express all types of production lots in this acyclic graph including "make-to-order" type production.

In the objective function of $U L S_{P(W C R)}$, an aggregate OWCR formulation is given. However, a $X_{t k}$-based formulation of NPV of OWCR is required for arc value calculations. In the former formulation, the OWCR of an operation is the product of the corresponding unit cost, $X_{t k}$, and the number of periods to finance. Considering the NPV of OWCR, the discount rates are different (decreasing) during the periods to finance. Thereby, the discounted OWCR depends on the period where the payment occurred. $W C R_{t k}^{\text {pur }}, W C R_{t k}^{\text {set }}, W C R_{t k}^{\text {prod }}$ and $W C R_{t k}^{I n v}$ respectively stand for the OWCR generated by operations of purchasing, set-up, production and inventory holding for producing the $X_{t k}$. For example, in purchasing raw material for the production of $X_{t k}$, the payment to supplier is made in period $t+r_{f}$ and the client's payment is received in period $k+r_{c}$. Therefore, the corresponding discounted OWCR represents all financial needs to be covered between $t+r_{f}$ and $k+r_{c}$. However, we are not able to ensure the timing order between the payment to supplier and the collection of clients payment. For this reason, we consider that we continue to finance the payment to the supplier until the end of the planning horizon as well as the payment from customer. The mathematical formulation can be written as $W C R_{t k}^{p u r}=$ $a X_{t k}\left[\sum_{j=t+r_{f}}^{T} \frac{1}{(1+\alpha)^{j}}-\sum_{j=k+r_{c}}^{T} \frac{1}{(1+\alpha)^{j}}\right]$. (By considering the financing cost of OWCR, the horizon is extended because some payments may be received from the client or sent to the supplier after 
the last period of the planning horizon).

This formula allows us to correctly cover the two cases whether the payment to supplier or client's payment occurs first. In the first case, a negative OWCR in purchasing will be obtained which can be considered as an additional refund for the OWCR of other operations. In the second case, $W C R_{t k}^{\text {pur }}$ is a positive financial need to finance.

Following the same concept, the OWCR in other operations can be formulated as

- $W C R_{t k}^{s e t}=\frac{s Y_{t}}{Q_{t}+\left(1-Y_{t}\right)} X_{t k} \sum_{j=t}^{k+r_{c}-1} \frac{1}{(1+\alpha)^{j}}$,

- $W C R_{t k}^{\text {prod }}=p X_{t k} \sum_{j=t}^{k+r_{c}-1} \frac{1}{(1+\alpha)^{j}}$

- and $W C R_{t k}^{I n v}=h X_{t k} \sum_{l=t}^{k-1} \sum_{j=l}^{k+r_{c}-1} \frac{1}{(1+\alpha)^{j}}$.

For WCR of inventory holding, if $k=t$ (i.e., $X_{t k}$ is produced for demand in the same period), then there is no inventory holding cost. Combining all these components, the total OWCR for all $X_{t k}$, denoted as $W C R_{t o t a l}$, can be written as follows:

$$
W C R_{\text {total }}=\sum_{t=1}^{T} \sum_{k=1}^{T}\left(W C R_{t k}^{p u r}+W C R_{t k}^{s e t}+W C R_{t k}^{p r o d}+W C R_{t k}^{I n v}\right)
$$

To simplify the NPV formulation, note that $a_{t}^{\prime}=a \frac{1}{(1+\alpha)^{t}}, s_{t}^{\prime}=s \frac{1}{(1+\alpha)^{\prime}}, p_{t}^{\prime}=p \frac{1}{(1+\alpha)^{t}}$ and $h_{t}^{\prime}=$ $h \frac{1}{(1+\alpha)^{\prime}}$. With the ZIO property, the arc values are presented as follows (with $L C_{t k}$ representing all the production costs):

$$
\begin{aligned}
E_{t k}= & L C_{t k}+\beta \sum_{l=t}^{k-1}\left(W C R_{t k}^{p u r}+W C R_{t k}^{s e t}+W C R_{t k}^{p r o d}+W C R_{t k}^{I n v}\right) \\
= & \left(a_{t+r_{f}}^{\prime}+p_{t}^{\prime}\right) \sum_{l=t}^{k-1} d_{l}+s_{t}^{\prime}+\sum_{l=t}^{k-1} d_{l} \sum_{i=t}^{l-1} h_{i}^{\prime} \\
& +\beta \sum_{l=t}^{k-1} d_{l}\left[\left(\sum_{j=t}^{T} a_{j+r_{f}}^{\prime}-\sum_{j=l}^{T} a_{j+r_{c}}^{\prime}\right)+\sum_{j=t}^{l+r_{c}-1} p_{j}^{\prime}+\sum_{j=t}^{l+r_{c}-1} \frac{s_{j}^{\prime}}{\sum_{i=t}^{k-1} d_{i}}+\sum_{i=t}^{l-1} \sum_{j=i}^{l+r_{c}-1} h_{j}^{\prime}\right]
\end{aligned}
$$


The computation of $E_{t k}$ is done in $\mathrm{O}\left(T^{2}\right)$. The objective of this algorithm is to find the shortest path to the last node. To do so, we need to progressively locate the shortest path to other nodes. We therefore examine all possible paths to each node from all its predecessors through the arc in between. This can be carried out by the recursive function

$$
\operatorname{Profit}[t]=\min _{j \in[1, t-1]}\left\{\operatorname{Profit}[j]+E_{j t}\right\}
$$

with Profit $[t]$ the minimum total cost to finance to satisfy all demands until period $t$. Thus, a dynamic programming algorithm is established as presented in Algorithm 1. The complexity of the algorithm is $\mathrm{O}\left(T^{4}\right)$, thus the $U L S_{P(W C R)}$ problem can be solved in polynomial time.

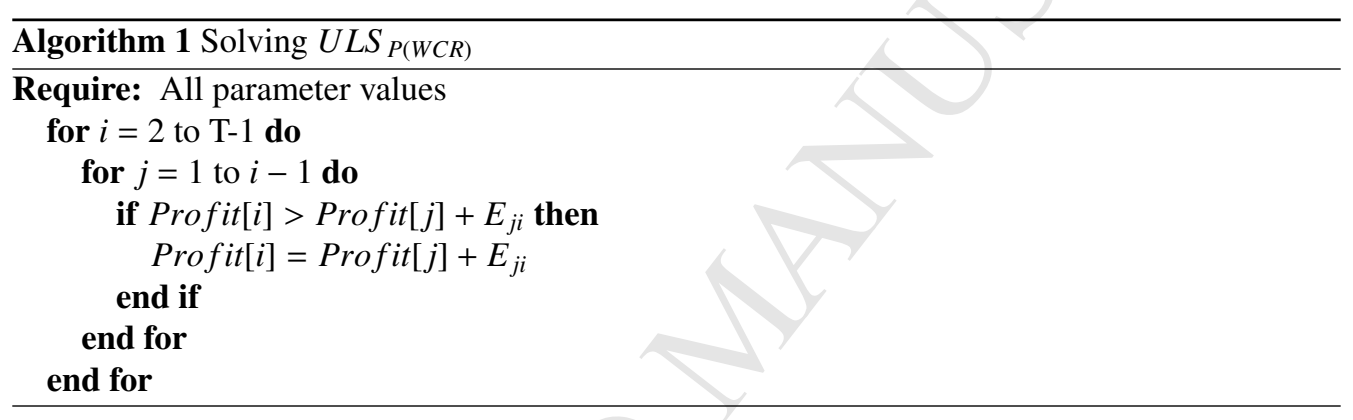

\section{Numerical examples}

Through the following numerical tests, we reveal differences between optimal production plans for profit maximization and costs minimization objectives. These tests illustrate the influence of considering the financing cost of OWCR on an optimal production program. With the proven ZIO property, the optimal program of profit maximization problem is calculated and denoted as $P_{w c r}^{o p t}$. Moreover, the optimal program of the traditional $U L S$ model is denoted as $P_{u l s}^{o p t}$. The tests are organized as follows:

- Firstly, a comparison between $P_{w c r}^{o p t}$ and $P_{u l s}^{o p t}$ with the same set of parameter values is provided to show the differences in the production programs;

- Secondly, the evolution of a production program following the variation of discount and interest rates is presented as well as the decrease of average inventory level; 
- Thirdly, we compare the objective value of $U L S$ and $U L S_{P(W C R)}$ model by applying respectively $P_{u l s}^{o p t}$ and $P_{w c r}^{o p t}$ in both models.

For the following tests, we use the demand of the instance of Trigeiro et al. (1989) (G-72, demand 7). Values of other parameters are set to adapt the ULS concept which considers only setup and inventory holding costs (see Table 5):

- Since the purchasing and production cost are not considered in the traditional ULS model, these unit costs are given as zero in order to compare the optimal programs under the same conditions. Accordingly, the delay in payment to the supplier involved only in purchasing is irrelevant in determining the production planning. Thus, $a=p=r_{f}=0$;

- The setup cost, $s$, is given as 600 and the unit cost of inventory holding per period, $h$, is fixed at 1 ;

- The delay in payments from customer, $r_{c}$ is set to 5 periods;

- The unit selling price will not be considered as it is a constant parameter and will not impact the production program. However, it should be taken into account for the periodic OWCR maximization objective.

\begin{tabular}{ll}
\multicolumn{2}{c}{ Table 5: Numerical example parameter values } \\
\hline Parameter & Value \\
\hline Purchasing unit cost, $a$ & 0 \\
Setup cost, $s$ & 600 \\
Production unit cost, $p$ & 0 \\
Inventory holding unit cost per period, $h$ & 1 \\
Delay in payment from customer, $r_{c}$ & 5 \\
Delay in payment to supplier, $r_{f}$ & 0 \\
Unit sales price & not considered \\
\hline
\end{tabular}

\subsection{Production program comparisons}

We compare optimal programs separately calculated by these two models with $\alpha=0.08$ and $\beta=0.1 . P_{w c r}^{o p t}$ and $P_{u l s}^{o p t}$ are illustrated in Figure 3. We observe that 
- The production programs are different. The $U L S$ model cannot always provide the optimal solution for maximizing the profit;

- The production lots of $P_{w c r}^{o p t}$ are smaller with a profit maximization objective compared with $P_{u l s}^{o p t}$ which leads to more setups and lower inventory levels on average;

The reason for this difference in production plans is the cumulative effect of financing the inventory holding costs of a product for all periods until sold. Considering the financial cost, more holding related cost is generated for each product held in inventory. In this case, fewer products are held in inventory during the horizon even though production and financial costs for setup costs are higher.

\subsection{Production program evolution with different rates of discount and interest}

In order to illustrate the influences of the two financial aspects (time value of money and financing cost of OWCR) on a production program, the discount and interest rates are respectively varied from 0.01 to 0.1 in steps of 0.01 . The result of the comparison is presented in Figure 4 . The bold grid represents the numbers of setups in optimal programs proposed by the $U L S_{P(W C R)}$ model and the light grid shows the number of setups in optimal programs in the ULS case (which remain unchanged). In this figure, observations can be summarized as follows:

- When the rates are very small, we obtain the same production program as the optimal ULS program;

- In other cases, the $P_{w c r}^{o p t}$ are different from $P_{u l s}^{o p t}$. Two more production lots may be planned for the financial model when the rates are relatively large.

Consequently, we first deduce from the second observation that considering the financial aspects radically changes the production program from the traditional ULS program which only optimizes logistic costs. Next, since $P_{w c r}^{o p t}$ generally proposes more setups, fewer products are held in inventory during the planning horizon compared with the ULS case. This decrease of average inventory level is presented numerically in Table 6 , which compares the average inventory level with $P_{u l s}^{o p t}$. For each rate combination, the difference in number of setups (\#Setup) and average 
level of inventory in percentage is given by $\Delta A v g$. Stock $=\frac{\operatorname{Inv} w c r-\operatorname{In} v_{u l s}}{\operatorname{In} v_{u l s}} \times 100 \%$, as presented in Table 6.

Table 6: Differences in number of setups and average inventory level between optimal programs of $U L S P(W C R)$ and $U L S$

\begin{tabular}{c|c|c|c|c|c}
\multicolumn{2}{c|}{ Parameter } & $\beta=0.01$ & $\beta=0.02$ & $\beta=0.08$ & $\beta=0.1$ \\
\hline \multirow{3}{*}{$\alpha=0.01$} & \#Setup & $=$ & $=$ & +1 & +1 \\
\cline { 2 - 6 } & $\Delta A v g$. Stock & 0 & 0 & $-14.2 \%$ & $-14.2 \%$ \\
\hline \multirow{3}{*}{$\alpha=0.02$} & \#Setup & $=$ & +1 & +1 & +1 \\
\cline { 2 - 6 } & $\Delta A v g$. Stock & 0 & $-14.2 \%$ & $-14.2 \%$ & $-14.2 \%$ \\
\hline \multirow{2}{*}{$\alpha=0.08$} & \#Setup & +1 & +1 & +1 & +2 \\
\cline { 2 - 6 } & $\Delta A v g$. Stock & $-14.08 \%$ & $-14.08 \%$ & $-14.08 \%$ & $-26.7 \%$ \\
\hline \multirow{3}{*}{$\alpha=0.1$} & \#Setup & +1 & +1 & +2 & +2 \\
\cline { 2 - 6 } & $\Delta A v g$. Stock & $-14.08 \%$ & $-14.08 \%$ & $-26.32 \%$ & $-26.32 \%$ \\
\hline
\end{tabular}

The difference between optimal programs becomes more significant when the financial rates increase. A large decrease of $26 \%$ of average inventory level can be reached with relatively high discount and interest rate according to these tests. Essentially, the financing cost of inventory holding cost is quickly increased due to the cumulative effect of a higher inventory level. As a consequence, it is undesirable to hold too much inventory when seeking to maximize the NPV of profit i.e., more frequent setups are preferred.

\subsection{Production and financial cost comparisons}

Within these tests, we find three cases where $P_{u l s}^{o p t}$ and $P_{w c r}^{o p t}$ are identical when the rates are small. For other cases, we compare the NPV of total costs including the financing cost of OWCR generated by $P_{u l s}^{o p t}$ and $P_{w c r}^{o p t}$, denoted respectively as $N P V_{u l s}$ and $N P V_{w c r}$. Since $P_{w c r}^{o p t}$ generates a minimum NPV of total cost, the increase of NPV in applying the $P_{u l s}^{o p t}$ is computed as $\triangle_{N P V} U L S=\frac{N P V_{u l s}-N P V_{w c r}}{N P V_{w c r}} \times 100 \%$. The result is presented in Figure $5\left(\Delta_{N P V} U L S_{P(W C R)}\right.$ represents the minimum NPV of total cost with $\left.P_{w c r}^{o p t}\right) . P_{u l s}^{o p t}$ generates a lower NPV of total cost by at most $3 \%$ compared with the NPV obtained by $P_{u l s}^{o p t}$.

However, because the production cost generated by $U L S$ model, denoted as $\log _{u l s}$ is already optimal, the increase of production cost generated by applying $P_{w c r}^{o p t}$ (denoted as $\log _{w c r}$ ) is logically higher. It is calculated as $\Delta_{L O G} U L S_{P}(W C R)=\frac{\log _{w c r}-\log _{u l s}}{\log _{u l s}} \times 100 \%$ and presented in 
Figure 6.

\subsection{Program evaluation with different purchasing costs and delays in payment to supplier}

Considering the delay in payment to supplier only affects the purchasing cost so we combine the tests of these two parameters as in Figure 7. In these tests, we vary the purchasing unit cost from 0 to 90 in steps of 10 . Moreover, the delay in payment to the supplier varies from 0 to 20 in steps of 2, and the rates are fixed at 3\%. First, we observe that following the increase of purchasing unit cost with a fixed delay, more production lots are launched which means that fewer products will be held in inventory. The reason is that when the purchasing cost is more expensive, it is preferred to launch production later considering the discount effect which make early activities more costly in term of NPV. Second, with a fixed purchasing unit cost and an increasing delay to the supplier, the production size will generally increase to keep more NPV of inventory value in the system and to return cash back to the supplier as late as possible.

\subsection{Program evaluation with different production unit costs}

Based on the parameter values given in Table 5 , we set the production unit cost at 5 and the rates at $3 \%$. The result is presented in Figure 8. The production lot size will decrease with an increasing production unit cost which means the productions are generally postponed. This is because that the NPV of the production costs is higher in an early period due to the discount effect and the number of periods to finance is greater if the production occurs in an early period.

\subsection{Program evaluation with different delays in payment from the client}

Similar tests are performed with the rates set at 5\%. Moreover, the purchasing and production unit cost are set equal to 10 . We then vary the delay in payment from client from 0 to 20 in steps of 2. The result is shown in Figure 9. We observe that the increasing delay in payment from the client causes a larger production lot size. This is due to postponing the periods for manufacturing the demand and paying the associated costs in later periods. 


\section{Conclusions}

In this paper, firstly, we propose a new generic model of operations-related working capital requirements. This type of model allows us to measure the evolution of OWCR over the planning horizon. Secondly, a dynamic lot-sizing-based profit maximization model is developed considering both the financing cost of OWCR and the time value of money. This model is established for the single-site, single-level, single-production and infinite production capacity case. After proving the Zero-Inventory-Ordering property of this problem, an exact method is built based on dynamic programming. With the polynomial-time algorithm, we are able to not only reach the optimal plan which maximizes the net present value of profit, but also evaluate the profitability of satisfying a series of demands. Numerical tests are provided to show the interest of applying our OWCR model compared with the classical ULS model. We find that we have less interest in holding products in inventory due to their dramatic amplification of financial costs. On the other hand, authors are nevertheless aware of the limits of this paper as the first study which theoretically considers the WCR cost in a classic dynamic lot-sizing problem. Immediate application for real-world problems remains a challenge, however, we believe this study contributes significantly to promoting further studies in more complex and realistic cases.

For future research may focus on reducing the complexity of the proposed algorithm by considering the approaches presented in Wagelmans et al. (1992), Aggarwal and Park (1993) and Federgruen and Tzur (1991) since this algorithm is close to that of Wagner-Whitin. Moreover, future research can be undertaken to consider time-varying cost parameters. In order to establish a global profitability evaluation, a two-level (customer-factory) profit maximization problem could also be addressed. Furthermore, the production capacity and risks in supply chain management should be taken into account among other extensions.

\section{Acknowledgment}

The authors gratefully acknowledge the valuable comments and suggestions of the anonymous referees. This work is supported by the Competitiveness Clusters of France under FUI 15 
project "Risk, Credit and Supply chain Management (RCSM)".

\section{References}

Aggarwal, A. and Park, J. K. (1993). Improved algorithms for economic lot size problems, Operations research 41(3): 549-571.

Aggarwal, S. and Jaggi, C. (1995). Ordering policies of deteriorating items under permissible delay in payments, Journal of the operational Research Society pp. 658-662.

Babich, V. and Sobel, M. J. (2004). Pre-ipo operational and financial decisions, Management Science 50(7): $935-948$.

Bei, Z. and Wijewardana, W. (2012). Working capital policy practice: Evidence from sri lankan companies, ProcediaSocial and Behavioral Sciences 40: 695-700.

Benito, A., Neiss, K. S., Price, S. and Rachel, L. (2010). The impact of the financial crisis on supply, Bank of England Quarterly Bulletin p. Q2.

Berling, P. and Rosling, K. (2005). The effects of financial risks on inventory policy, Management Science 51(12): 18041815.

Birge, J. R. (2014). Om forum - operations and finance interactions, Manufacturing $\mathcal{E}$ Service Operations Management 17(1): 4-15.

Brahimi, N., Absi, N., Dauzère-Pérès, S. and Nordli, A. (2017). Single-item dynamic lot-sizing problems: An updated survey, European Journal of Operational Research .

Buchmann, P., Roos, A., Jung, U. and Martin, A. (2008). Cash for growth: The neglected power of working-capital management, BCG Opportunities for Actions. Available Online: http://www. bcg. com. cn/en/files/publications/articles_pdf/Cash_for_Growth_May_2008. pdf [Accessed Mai 18 2014] .

Chao, X., Chen, J. and Wang, S. (2008). Dynamic inventory management with cash flow constraints, Naval Research Logistics (NRL) 55(8): 758-768.

Chen, T.-L., Lin, J. T. and Wu, C.-H. (2014). Coordinated capacity planning in two-stage thin-film-transistor liquidcrystal-display (tft-lcd) production networks, Omega 42(1): 141-156.

Comelli, M., Gourgand, M. and Lemoine, D. (2006). A review of tactical planning models, 1: 594-600.

Cooper, M. C., Lambert, D. M. and Pagh, J. D. (1997). Supply chain management: more than a new name for logistics, The international journal of logistics management 8(1): 1-14.

Ding, S., Guariglia, A. and Knight, J. (2013). Investment and financing constraints in china: does working capital management make a difference?, Journal of Banking E Finance 37(5): 1490-1507.

Enqvist, J., Graham, M. and Nikkinen, J. (2014). The impact of working capital management on firm profitability in different business cycles: Evidence from finland, Research in International Business and Finance 32: 36-49.

Ernst, Y. (2010). All tied up, White paper, working capital management report .

Ernst, Y. (2012). All tied up, White paper, working capital management report .

Federgruen, A. and Tzur, M. (1991). A simple forward algorithm to solve general dynamic lot sizing models with n periods in 0 (n $\log \mathrm{n})$ or 0 (n) time, Management Science 37(8): 909-925. 
Gupta, D. and Wang, L. (2009). A stochastic inventory model with trade credit, Manufacturing $\mathcal{E}$ Service Operations Management 11(1): 4-18.

Harris, F. W. (1913). How many parts to make at once, Operations Research 38(6): 947-950.

Helber, S. (1998). Cash-flow oriented lot sizing in mrp ii systems, Beyond Manufacturing Resource Planning (MRP II) Springer, pp. 147-183.

Hofmann, E. and Kotzab, H. (2010). A supply chain-oriented approach of working capital management, Journal of Business Logistics 31(2): 305-330.

Jensen, M. C. (2001). Value maximization, stakeholder theory, and the corporate objective function, Journal of applied corporate finance 14(3): 8-21.

Kieschnick, R., Laplante, M. and Moussawi, R. (2013). Working capital management and shareholders wealth, Review of Finance 17(5): 1827-1852.

Lim, J. S., Abdul Manan, Z., Hashim, H. and Wan Alwi, S. R. (2013). Optimal multi-site resource allocation and utility planning for integrated rice mill complex, Industrial $\mathcal{E}$ Engineering Chemistry Research 52(10): 3816-3831.

Lind, L., Pirttilä, M., Viskari, S., Schupp, F. and Kärri, T. (2012). Working capital management in the automotive industry: Financial value chain analysis, Journal of purchasing and supply management 18(2): 92-100.

Liu, Z. and Cruz, J. M. (2012). Supply chain networks with corporate financial risks and trade credits under economic uncertainty, International Journal of Production Economics 137(1): 55-67.

Lusa, A., Martínez-Costa, C. and Mas-Machuca, M. (2012). An integral planning model that includes production, selling price, cash flow management and flexible capacity, International Journal of Production Research 50(6): 1568-1581.

Martínez-Costa, C., Mas-Machuca, M., Benedito, E. and Corominas, A. (2014). A review of mathematical programming models for strategic capacity planning in manufacturing, International Journal of Production Economics 153: 66-85.

Mitra, S., Pinto, J. M. and Grossmann, I. E. (2014). Optimal multi-scale capacity planning for power-intensive continuous processes under time-sensitive electricity prices and demand uncertainty. part i: Modeling, Computers $\mathcal{E}$ Chemical Engineering 65: 89-101.

Modigliani, F. and Miller, M. H. (1958). The cost of capital, corporation finance and the theory of investment, The American economic review 48(3): 261-297.

Mun, S. G. and Jang, S. S. (2015). Working capital, cash holding, and profitability of restaurant firms, International Journal of Hospitality Management 48: 1-11.

Protopappa-Sieke, M. and Seifert, R. W. (2010). Interrelating operational and financial performance measurements in inventory control, European Journal of Operational Research 204(3): 439-448.

Raghavan, N. S. and Mishra, V. K. (2011). Short-term financing in a cash-constrained supply chain, International Journal of Production Economics 134(2): 407-412.

Serrano, A., Oliva, R. and Kraiselburd, S. (2017). On the cost of capital in inventory models with deterministic demand, International Journal of Production Economics 183: 14-20.

Taleizadeh, A. A. and Nematollahi, M. (2014). An inventory control problem for deteriorating items with back-ordering 
and financial considerations, Applied Mathematical Modelling 38(1): 93-109.

Theodore Farris, M. and Hutchison, P. D. (2002). Cash-to-cash: the new supply chain management metric, International Journal of Physical Distribution $\mathcal{E}$ Logistics Management 32(4): 288-298.

Thomas, B. G. and Bollapragada, S. (2010). General electric uses an integrated framework for product costing, demand forecasting, and capacity planning of new photovoltaic technology products, Interfaces 40(5): 353-367.

Timme, S. and Williams-Timme, C. (2000). The financial-scm connection., Supply Chain Management Review 4(2): 3340.

Trigeiro, W. W., Thomas, L. J. and McClain, J. O. (1989). Capacitated lot sizing with setup times, Management science 35(3): 353-366.

Trippi, R. R. and Lewin, D. E. (1974). A present value formulation of the classical eoq problem, Decision Sciences 5(1): 30-35.

Vahid, T. K., Elham, G., khosroshahi Mohsen, A. and Mohammadreza, E. (2012). Working capital management and corporate performance: evidence from iranian companies, Procedia-Social and Behavioral Sciences 62: 1313-1318.

Vidal, C. J. and Goetschalckx, M. (2001). A global supply chain model with transfer pricing and transportation cost allocation, European Journal of Operational Research 129(1): 134-158.

Wagelmans, A., Van Hoesel, S. and Kolen, A. (1992). Economic lot sizing: an o (n log n) algorithm that runs in linear time in the wagner-whitin case, Operations Research 40(1-supplement-1): S145-S156.

Wagner, H. M. and Whitin, T. M. (1958). Dynamic version of the economic lot size model, Management science 5(1): 89-96.

Wang, K.-J., Wang, S.-M. and Yang, S.-J. (2007b). A resource portfolio model for equipment investment and allocation of semiconductor testing industry, European Journal of Operational Research 179(2): 390-403.

Wang, S., Chen, J. and Wang, K.-J. (2007a). Resource portfolio planning of make-to-stock products using a constraint programming-based genetic algorithm, Omega 35(2): 237-246.

Wu, J., Al-Khateeb, F. B., Teng, J.-T. and Cárdenas-Barrón, L. E. (2016). Inventory models for deteriorating items with maximum lifetime under downstream partial trade credits to credit-risk customers by discounted cash-flow analysis, International Journal of Production Economics 171: 105-115.

Zeballos, A. C., Seifert, R. W. and Protopappa-Sieke, M. (2013). Single product, finite horizon, periodic review inventory model with working capital requirements and short-term debt, Computers $\mathcal{E}$ Operations Research 40(12): 2940-2949.

Zhao, L. and Huchzermeier, A. (2015). Operations-finance interface models: A literature review and framework, European Journal of Operational Research 244(3): 905-917.

\section{Appendix A. Proof of Theorem}

Firstly, we denote that:

- $X^{U L S_{P(W C R)}}$ represents all feasible solution in term of $X_{t k}$; 
- $P$ is a production plan;

- Profit $(P)$ stands for the objective value in the proposed model with $P$.

Definition 1. A production planning is complied with the ZIO property if and only if the production is only planned when the inventory level drops to zero. With our notation, it can be expressed mathematically as

$$
Q_{t} \times\left[\sum_{k=1}^{t-1}\left(\sum_{l=t}^{T} X_{k, l}\right)\right]=0 \quad \forall t \in[2, T]
$$

In other words, it can be written as:

$$
\left\{\begin{array}{llll}
Q_{t}>0 & \Rightarrow & X_{k, l}=0 & \forall(k, l) \in[1, t-1] \times[t, T] \\
X_{k, l}>0 & \Rightarrow & Q_{t}=0 & \forall t \in[k+1, l]
\end{array}\right.
$$

Conjecture Appendix A.1. There is a plan $P^{*} \in X^{\left(U L S_{P(B F R)}\right)}$ which verifies the ZIO property while

$$
\operatorname{Profit}\left(P^{*}\right)=\max _{P \in X^{\left(U L S_{P(B F R)}\right)}} \operatorname{Profit}(P)
$$

Let $(P) \in X^{\left(U L S_{P(B F R)}\right)}$ be a planning which does not comply with the ZIO property. Note that $(t, m, n) \in[1, T]^{3}$ is a triplet with $m<t \leq n$ and a violation of the property can be presented as $Q_{t} \times X_{m, n}>0$. Then, we assume that several violations can be found in $P$.

$$
\begin{aligned}
& X_{k, t}^{\prime}=X_{k, t} \quad \forall(k, t) \in[1, T]^{2}-\{(m, n),(t, n)\} \\
& X_{m, n}^{\prime}=0 \\
& X_{t, n}^{\prime}=X_{t, n}+X_{m, n}
\end{aligned}
$$

According to the above-mentioned definition, we find one less violation of the property in $P^{\prime}$ than in $P$. We now need to prove that $\operatorname{Profit}(P)-\operatorname{Profit}\left(P^{\prime}\right) \leq 0$. To do so, we go through each term of the objective function. To simplify the NPV formulation, note that $a_{t}^{\prime}=a \frac{1}{(1+\alpha)^{t}}, s_{t}^{\prime}=s \frac{1}{(1+\alpha)^{t}}$, $p_{t}^{\prime}=p \frac{1}{(1+\alpha)^{t}}, h_{t}^{\prime}=h \frac{1}{(1+\alpha)^{t}}$ and $v_{t}^{\prime}=v \frac{1}{(1+\alpha)^{t}}$. Essentially, these cost parameters decrease over time. 
In the following proof, we examine the difference of all terms in the objective functions, $P$ and $P^{\prime}$, respectively the revenue, the logistic cost and the OWCR financing cost. At first, there is no difference in NPV of Revenue between these two plans. This is because the demand and unit selling price (as well as discounted unit selling price.) are identical over planning horizon. Thus, $R(P)-R\left(P^{\prime}\right)=0$. Then, the difference in logistic cost can therefore be written as:

$$
\begin{aligned}
L C(P)-L C\left(P^{\prime}\right) & =\sum_{j=1}^{T}\left[a_{j-r_{f}}^{\prime}\left(Q_{j-r_{f}}-Q_{j-r_{f}}^{\prime}\right)+p_{j}^{\prime}\left(Q_{j}-Q_{j}^{\prime}\right)+s_{j}^{\prime}\left(Y_{j}-Y_{j}^{\prime}\right)+h_{j}^{\prime}\left(I_{j}-I_{j}^{\prime}\right)\right] \\
& =X_{m, n}\left(a_{m-r_{f}}^{\prime}-a_{t-r_{f}}^{\prime}\right)+X_{m, n}\left(p_{m}^{\prime}-p_{t}^{\prime}\right)+s_{t}^{\prime}\left(Y_{m}-Y_{m}^{\prime}\right)+X_{m, n} \sum_{j=m}^{t-1} h_{j}^{\prime}
\end{aligned}
$$

Since $m<t$ and $Y_{m} \geq Y_{m}^{\prime}$, we obtain:

$$
L C(P)-L C\left(P^{\prime}\right)>0
$$

Next, for OWCR financing cost, we examine its components one by one:

Firstly, since we apply constant unit costs to calculate purchasing, production and inventory holding costs, comparison on these operations are relatively direct as follows:

$$
\begin{aligned}
& W C R^{p u r}(P)-W C R^{p u r}\left(P^{\prime}\right)=\sum_{t=1}^{T} \sum_{k=t}^{T} a X_{t k}\left[\sum_{j=t}^{T} \frac{1}{(1+\alpha)^{j+r_{f}}}-\sum_{j=k}^{T} \frac{1}{(1+\alpha)^{j+r_{c}}}\right] \\
& -\sum_{t=1}^{T} \sum_{k=t}^{T} a X_{t k}^{\prime}\left[\sum_{j=t}^{T} \frac{1}{(1+\alpha)^{j+r_{f}}}-\sum_{j=k}^{T} \frac{1}{(1+\alpha)^{j+r_{c}}}\right] \\
& =X_{m, n}\left[\sum_{j=m}^{T} a_{j}^{\prime}-\sum_{j=t}^{T} a_{j}^{\prime}\right]=X_{m, n} \sum_{j=m}^{t-1} a_{j}^{\prime}>0 \\
& W C R^{\text {prod }}(P)-W C R^{\text {prod }}\left(P^{\prime}\right)=\sum_{t=1}^{T} \sum_{k=t}^{T} p X_{t k} \sum_{j=t}^{k+r_{c}-1} \frac{1}{(1+\alpha)^{t}}-\sum_{t=1}^{T} \sum_{k=t}^{T} p X_{t k}^{\prime} \sum_{j=t}^{k+r_{c}-1} \frac{1}{(1+\alpha)^{t}} \\
& =X_{m, n}\left[\sum_{j=m}^{k+r_{c}-1} p_{j}^{\prime}-\sum_{j=t}^{k+r_{c}-1} p_{j}^{\prime}\right]=X_{m, n} \sum_{j=m}^{t-1} p_{j}^{\prime}>0
\end{aligned}
$$




$$
\begin{aligned}
W C R^{i n v}(P)-W C R^{i n v}\left(P^{\prime}\right) & =\sum_{t=1}^{T} \sum_{k=t}^{T} h X_{t k} \sum_{l=t}^{k-1} \sum_{j=l}^{k+r_{c}-1} \frac{1}{(1+\alpha)^{t}}-\sum_{t=1}^{T} \sum_{k=t}^{T} h X_{t k}^{\prime} \sum_{l=t}^{k-1} \sum_{j=l}^{k+r_{c}-1} \frac{1}{(1+\alpha)^{t}} \\
& =X_{m, n}\left(\sum_{l=m}^{n-1} \sum_{j=l}^{n+r_{c}-1} h_{j}^{\prime}-\sum_{l=t}^{n-1} \sum_{j=l}^{n+r_{c}-1} h_{j}^{\prime}\right) \\
& =X_{m, n}\left(\sum_{l=m}^{m+n-t-1} \sum_{k=0}^{m-t-1}\left(h_{k}^{\prime} \frac{1}{(1+\alpha)^{l}}\right)+\sum_{l=m+n-t}^{n-1} \sum_{j=l}^{n+r_{c}-1} h_{j}^{\prime}\right)>0
\end{aligned}
$$

Since the cost parameters are all positive, we confirm that the OWCR of these three operations is greater with $P$ than the OWCR with $P^{\prime}$.

We now focus on the difference in OWCR of set-up. The difficulty comes from the fact that the shared set-up cost per product (in period $m$ and $t$ ) changes with the quantity of $X_{t k}$ :

$$
\begin{aligned}
W C R^{s e t}(P)-W C R^{s e t}\left(P^{\prime}\right)= & \sum_{t=1}^{T} \sum_{k=t}^{T} \frac{s Y_{t} X_{t k}}{Q_{t}+\left(1-Y_{t}\right)} X_{t k} \sum_{j=t}^{k+r_{c}-1} \frac{1}{(1+\alpha)^{t}} \\
& -\sum_{t=1}^{T} \sum_{k=t}^{T} \frac{s Y_{t} X_{t k}}{Q_{t}+\left(1-Y_{t}\right)} X_{t k} \sum_{j=t}^{k+r_{c}-1} \frac{1}{(1+\alpha)^{t}} \\
= & \sum_{k=m}^{T} X_{m, k} \sum_{j=m}^{k+r_{c}-1} \frac{s_{j}^{\prime} Y_{m}}{Q_{m}+\left(1-Y_{m}\right)}+\sum_{k=t}^{T} X_{t k} \sum_{j=t}^{k+r_{c}-1} \frac{s_{j}^{\prime} Y_{t}}{Q_{t}+\left(1-Y_{t}\right)} \\
& -\sum_{k=m}^{T} X_{m, k}^{\prime} \sum_{j=m}^{k+r_{c}-1} \frac{s_{j}^{\prime} Y_{m}^{\prime}}{Q_{m}^{\prime}+\left(1-Y_{m}^{\prime}\right)}-\sum_{k=t}^{T} X_{t k}^{\prime} \sum_{j=t}^{k+r_{c}-1} \frac{s_{j}^{\prime} Y_{t}^{\prime}}{Q_{t}^{\prime}+\left(1-Y_{t}^{\prime}\right)} \\
= & \underbrace{\sum_{k=m}^{T}\left(X_{m, k} \sum_{j=m}^{k+r_{c}-1} \frac{s_{j}^{\prime} Y_{m}}{Q_{m}+\left(1-Y_{m}\right)}-X_{m, k}^{\prime} \sum_{j=m}^{k+r_{c}-1} \frac{s_{j}^{\prime} Y_{m}^{\prime}}{Q_{m}^{\prime}+\left(1-Y_{m}^{\prime}\right)}\right)}_{\text {Parr }} \\
& +\underbrace{\sum_{k=t}^{T}\left(X_{t k} \sum_{j=t}^{k+r_{c}-1} \frac{s_{j}^{\prime} Y_{t}}{Q_{t}+\left(1-Y_{t}\right)}-X_{t k}^{\prime} \sum_{j=t}^{k+r_{c}-1} \frac{s_{j}^{\prime} Y_{t}^{\prime}}{Q_{t}^{\prime}+\left(1-Y_{t}^{\prime}\right)}\right)}_{\text {Part } 1}
\end{aligned}
$$

Next, we evaluate part 1. Two possible cases are discussed in following paragraphs:

Case 1: $Q_{m}^{\prime}=0$. In this case,

$$
\text { Part } 1=\sum_{k=m}^{T} X_{m, k} \sum_{j=m}^{k+r_{c}-1} \frac{s_{j}^{\prime} Y_{m}}{Q_{m}+\left(1-Y_{m}\right)}=\sum_{k=m}^{T} X_{m, k} \sum_{j=m}^{k+r_{c}-1} \frac{s_{j}^{\prime}}{Q_{m}}>0
$$

Case 2: $Q_{m}^{\prime}>0$. In this case, 


$$
\begin{aligned}
\text { Part } 1 & =\sum_{k=m}^{T}\left(X_{m, k} \sum_{j=m}^{k+r_{c}-1} \frac{s_{j}^{\prime} Y_{m}}{Q_{m}+\left(1-Y_{m}\right)}-X_{m, k}^{\prime} \sum_{j=m}^{k+r_{c}-1} \frac{s_{j}^{\prime} Y_{m}^{\prime}}{Q_{m}^{\prime}+\left(1-Y_{m}^{\prime}\right)}\right) \\
& =\sum_{k=m}^{T}\left(X_{m, k} \sum_{j=m}^{k+r_{c}-1} \frac{1}{Q_{j}^{\prime}}-X_{m, k}^{\prime} \sum_{j=m}^{k+r_{c}-1} \frac{s_{j}^{\prime}}{Q_{m}^{\prime}}\right) \\
& =\frac{1}{Q_{m} Q_{m}^{\prime}} \sum_{k=m}^{T} \sum_{j=m}^{k+r_{c}-1} s_{j}^{\prime}\left(X_{m, k} Q_{m}^{\prime}-X_{m, k}^{\prime} Q_{m}^{\prime+r_{c}-1} s_{j=m}^{\prime} X_{m, n} Q_{m}^{\prime}+\sum_{k=m, k \neq n}^{T} \sum_{j=m}^{k+r_{c}-1} s_{j}^{\prime}\left(X_{m, k}^{\prime} Q_{m}^{\prime}-X_{m, k}^{\prime} Q_{m}\right)\right] \\
& =\frac{1}{Q_{m} Q_{m}^{\prime}}\left[\sum_{j=m}^{n+r_{c}-1} s_{j}^{\prime} X_{m, n} Q_{m}^{\prime}+\sum_{k=m, k \neq n}^{T} \sum_{j=m}^{k+r_{c}-1} s_{j}^{\prime}\left(X_{m, k}^{\prime} Q_{m}^{\prime}-X_{m, k}^{\prime}\left(Q_{m}^{\prime}+X_{m, n}\right)\right)\right] \\
& =\frac{1}{Q_{m} Q_{m}^{\prime}}\left[\sum_{j=m}^{n+r_{c}-1} s_{j}^{\prime} X_{m, n} Q_{m}^{\prime}-\sum_{k=m, k \neq n}^{T} \sum_{j=m}^{k+r_{c}-1} s_{j}^{\prime} X_{m, k}^{\prime} X_{m, n}\right] \\
& =\frac{X_{m, n}}{Q_{m} Q_{m}^{\prime}}\left[\sum_{j=m}^{n+r_{c}-1} s_{j}^{\prime} Q_{m}^{\prime}-\sum_{k=m, k \neq n}^{T} \sum_{j=m}^{k+r_{c}-1} s_{j}^{\prime} X_{m, k}^{\prime}\right] \\
& =\frac{X_{m, n}}{Q_{m} Q_{m}^{\prime}}\left[\sum_{j=m}^{n+r_{c}-1} s_{j}^{\prime} \sum_{k=m}^{t-1} X_{m, k}^{\prime}-\sum_{k=m}^{t-1} \sum_{j=m}^{k+r_{c}-1} s_{j}^{\prime} X_{m, k}^{\prime}\right] \\
& =\frac{X_{m, n}}{Q_{m} Q_{m}^{\prime}} \sum_{k=m}^{t-1} X_{m, k}\left(\sum_{j=m}^{n+r_{c}-1} s_{j}^{\prime}-\sum_{j=m}^{k+r_{c}-1} s_{j}^{\prime}\right) \\
& =\frac{X_{m, n}}{Q_{m} Q_{m}^{\prime}} \sum_{k=m}^{t-1} X_{m, k} \sum_{j=k+r_{c}-1}^{n+r_{c}-1} s_{j}^{\prime}>0
\end{aligned}
$$

Thus, part 1 is positive in all cases. We then go through the part 2:

$$
\begin{aligned}
\text { Part 2 } & =\sum_{k=t}^{T}\left(X_{t k} \sum_{j=t}^{k+r_{c}-1} \frac{s_{j}^{\prime} Y_{t}}{Q_{t}+\left(1-Y_{t}\right)}-X_{t k}^{\prime} \sum_{j=t}^{k+r_{c}-1} \frac{s_{j}^{\prime} Y_{t}^{\prime}}{Q_{t}^{\prime}+\left(1-Y_{t}^{\prime}\right)}\right) \\
& =\sum_{k=t}^{T}\left(\frac{X_{t k}}{Q_{t}} \sum_{j=t}^{k+r_{c}-1} s_{j}^{\prime}-\frac{X_{t k}^{\prime}}{Q_{t}^{\prime}} \sum_{j=t}^{k+r_{c}-1} s_{j}^{\prime}\right) \\
& =\frac{1}{Q_{t} Q_{t}^{\prime}} \sum_{k=t}^{T}\left(X_{t k} Q_{t}^{\prime} \sum_{j=t}^{k+r_{c}-1} s_{j}^{\prime}-X_{t k}^{\prime} Q_{t} \sum_{j=t}^{k+r_{c}-1} s_{j}^{\prime}\right) \\
& =\frac{1}{Q_{t} Q_{t}^{\prime}} \sum_{k=t}^{T}\left(X_{t k}\left(Q_{t}+X_{m, n}\right) \sum_{j=t}^{k+r_{c}-1} s_{j}^{\prime}-X_{t k}^{\prime} Q_{t} \sum_{j=t}^{k+r_{c}-1} s_{j}^{\prime}\right) \\
& =\frac{1}{Q_{t} Q_{t}^{\prime}} \sum_{k=t}^{T}\left(X_{t k} X_{m, n} \sum_{j=t}^{k+r_{c}-1} s_{j}^{\prime}-Q_{t}\left(X_{t k}-X_{t k}^{\prime} \sum_{j=t}^{k+r_{c}-1} s_{j}^{\prime}\right)\right.
\end{aligned}
$$




$$
=\frac{1}{Q_{t} Q_{t}^{\prime}}\left(\sum_{k=t}^{T} X_{t k} X_{m, n} \sum_{j=t}^{k+r_{c}-1} s_{j}^{\prime}-Q_{t} X_{m, n} \sum_{j=t}^{n+r_{c}-1} s_{j}^{\prime}\right)
$$

In order to determine the sign of part2, two following cases must be carefully examined:

Case A: $Q_{t}^{\prime} \geq Q_{m}$. We have

$$
\frac{X_{m, n}}{Q_{t}^{\prime}} \sum_{j=n}^{n+r_{c}-1} s_{j}^{\prime}<\frac{X_{m, n}}{Q_{m}} \sum_{j=n}^{n+r_{c}-1} s_{j}^{\prime}
$$

Then, we attempt to compare this element with part 1:

Case A-1: $Q_{m}^{\prime}=0$. In this case,

$$
\begin{aligned}
\text { Part 1 } & =\sum_{k=m}^{T} \frac{X_{m, k}}{Q_{m}} \sum_{j=m}^{k+r_{c}-1} s_{j}^{\prime} \\
& =\sum_{k=m, k \neq n}^{T} \frac{X_{m, k}}{Q_{m}} \sum_{j=m}^{k+r_{c}-1} s_{j}^{\prime}+\frac{X_{m, n}}{Q_{m}} \sum_{j=n}^{n+r_{c}-1} s_{j}^{\prime} \\
& \geq \frac{X_{m, n}}{Q_{m}} \sum_{j=n}^{n+r_{c}-1} s_{j}^{\prime} q \\
& \geq \frac{X_{m, n}}{Q_{m}} \sum_{j=n}^{n+r_{c}-1} s_{j}^{\prime}
\end{aligned}
$$

Then, Part $1+$ Part $2 \geq \frac{X_{m, n}}{Q_{m}} \sum_{j=n}^{n+r_{c}-1} s_{j}^{\prime}-\frac{X_{m, n}}{Q_{t}^{\prime}} \sum_{j=n}^{n+r_{c}-1} s_{j}^{\prime} \geq\left(\frac{X_{m, n}}{Q_{t}^{\prime}}-\frac{X_{m, n}}{Q_{t}^{\prime}}\right) \sum_{j=n}^{n+r_{c}-1} s_{j}^{\prime}>0$ with $Q_{t}^{\prime} \geq Q_{m}$

Case A-2: $Q_{m}^{\prime}>0$. In this case,

$$
\begin{aligned}
\text { Part 1 } & =\frac{X_{m, n}}{Q_{m} Q_{m}^{\prime}} \sum_{k=m}^{t-1} X_{m, k} \sum_{j=k+r_{c}-1}^{n+r_{c}-1} s_{j}^{\prime} \\
& =\frac{X_{m, n}}{Q_{m} Q_{m}^{\prime}} \sum_{k=m}^{t-1} X_{m, k}\left(\sum_{j=m}^{n+r_{c}-1} s_{j}^{\prime}-\sum_{j=m}^{k+r_{c}-1} s_{j}^{\prime}\right) \\
& \geq \frac{X_{m, n}}{Q_{m} Q_{m}^{\prime}} \sum_{k=m}^{t-1} X_{m, k}\left(\sum_{j=m}^{n+r_{c}-1} s_{j}^{\prime}-\sum_{j=m}^{t+r_{c}-1} s_{j}^{\prime}\right)
\end{aligned}
$$




$$
\begin{aligned}
& \geq \frac{X_{m, n}}{Q_{m}}\left(\sum_{j=m}^{n+r_{c}-1} s_{j}^{\prime}-\sum_{j=m}^{t+r_{c}-1} s_{j}^{\prime}\right) \\
& \geq \frac{X_{m, n}}{Q_{t}^{\prime}}\left(\sum_{j=m}^{n+r_{c}-1} s_{j}^{\prime}-\sum_{j=m}^{t+r_{c}-1} s_{j}^{\prime}\right) \\
& =\frac{X_{m, n}}{Q_{t}^{\prime}} \sum_{j=t+r_{c}-1}^{n+r_{c}-1} s_{j}^{\prime}
\end{aligned}
$$

Moreover, we have:

$$
\begin{gathered}
\frac{1}{Q_{t} Q_{t}^{\prime}} \sum_{k=t}^{T} X_{t k} X_{m, n} \sum_{j=t}^{k+r_{c}-1} s_{j}^{\prime} \geq \\
\frac{X_{m, n}}{Q_{t} Q_{t}^{\prime}} \sum_{k=t}^{T} X_{t k} \sum_{j=t}^{k+r_{c}-1} s_{j}^{\prime} \geq \\
\frac{X_{m, n}}{Q_{t} Q_{t}^{\prime}} \sum_{k=t}^{T} X_{t k} \sum_{j=t}^{t+r_{c}-1} s_{j}^{\prime} \geq \\
\frac{X_{m, n}}{Q_{t} Q_{t}^{\prime}} \sum_{j=t}^{t+r_{c}-1} s_{j}^{\prime} \sum_{k=t}^{T} X_{t k} \geq \\
\frac{X_{m, n}}{Q_{t}^{\prime}} \sum_{j=t}^{t+r_{c}-1} s_{j}^{\prime}
\end{gathered}
$$

Thus, with (A.1) and (A.2),

$$
\text { Part } 1+\text { Part } 2 \geq \frac{X_{m, n}}{Q_{t}^{\prime}} \sum_{j=t+r_{c}-1}^{n+r_{c}-1} s_{j}^{\prime}+\frac{X_{m, n}}{Q_{t}^{\prime}} \sum_{j=t}^{t+r_{c}-1} s_{j}^{\prime}-\frac{X_{m, n}}{Q_{t}^{\prime}} \sum_{j=t}^{n+r_{c}-1} s_{j}^{\prime} \geq 0
$$

In this case, the sum of part 1 and part 2 is also positive.

Case B: $Q_{t}^{\prime}<Q_{m}$.

We distinguish again both cases of part 1:

Case B-1: $Q_{m}^{\prime}=0$. Impossible because $Q_{t}^{\prime} \geq Q_{m}$.

Case B-2: $Q_{m}^{\prime}>0$. Part 1 can be transformed as follows: 


$$
\begin{aligned}
\frac{X_{m, n}}{Q_{m} Q_{m}^{\prime}} \sum_{k=m}^{t-1} X_{m, k} \sum_{j=k+r_{c}-1}^{n+r_{c}-1} s_{j}^{\prime} & \geq \\
\frac{X_{m, n}}{Q_{m} Q_{m}^{\prime}} \sum_{j=t+r_{c}-2}^{n+r_{c}-1} s_{j}^{\prime} \sum_{k=m}^{t-1} X_{m, k} & \geq \\
\frac{X_{m, n}}{Q_{m} Q_{m}^{\prime}} \sum_{j=t+r_{c}-2}^{n+r_{c}-1} s_{j}^{\prime} Q_{m}^{\prime} & \geq \\
\frac{X_{m, n}}{Q_{m}} \sum_{j=t+r_{c}-2}^{n+r_{c}-1} s_{j}^{\prime} &
\end{aligned}
$$

Part 2 can be formulated as:

$$
\begin{aligned}
& \frac{1}{Q_{t} Q_{t}^{\prime}}\left(\sum_{k=t}^{T} X_{t k} X_{m, n} \sum_{j=t}^{k+r_{c}-1} s_{j}^{\prime}-Q_{t} X_{m, n} \sum_{j=t}^{n+r_{c}-1} s_{j}^{\prime}\right)= \\
& \frac{X_{m, n}}{Q_{t} Q_{t}^{\prime}}\left(\sum_{k=t}^{T} X_{t k} \sum_{j=t}^{k+r_{c}-1} s_{j}^{\prime}-Q_{t} \sum_{j=t}^{n+r_{c}-1} s_{j}^{\prime}\right) \geq \\
& \frac{X_{m, n}}{Q_{t} Q_{t}^{\prime}}\left(\sum_{j=t}^{t+r_{c}-1} s_{j}^{\prime}\left(\sum_{k=t}^{T} X_{t k}\right)-Q_{t} \sum_{j=t}^{n+r_{c}-1} s_{j}^{\prime}\right) \geq \\
& \frac{X_{m, n}}{Q_{t} Q_{t}^{\prime}}\left(\sum_{j=t}^{t+r_{c}-1} s_{j}^{\prime} Q_{t}-Q_{t} \sum_{j=t}^{n+r_{c}-1} s_{j}^{\prime}\right) \geq \\
&-\frac{X_{m, n}}{Q_{t}^{\prime}} \sum_{j=t+r_{c}-1}^{n+r_{c}-1} s_{j}^{\prime} \geq \\
&-\frac{X_{m, n}}{Q_{m}} \sum_{j=t+r_{c}-1}^{n+r_{c}-1} s_{j}^{\prime}
\end{aligned}
$$

In consequence,

$$
\text { Part 1 + Part } 2=\frac{X_{m, n}}{Q_{m}} \sum_{j=t+r_{c}-2}^{n+r_{c}-1} s_{j}^{\prime}-\frac{X_{m, n}}{Q_{m}} \sum_{j=t+r_{c}-1}^{n+r_{c}-1} s_{j}^{\prime} \geq \frac{X_{m, n}}{Q_{m}} s_{t+r_{c}-2}^{\prime} \geq 0
$$

To summarize, the sum of part 1 and part 2 is positive in all cases which means $P$ generates a bigger OWCR financing cost than $P^{\prime}$. To conclude, considering all above-mentioned comparisons, the NPV of revenue is equal with these two plans, but the NPV of the total cost is greater with $P$. Therefore, we favor the $P^{\prime}$ which has one less violation of ZIO property. In general, we are able to deduce that the optimal planning is the ZIO type planning with no violations at all. 